\title{
Refractory Small Lymphocytic Lymphoma
}

National Cancer Institute

\section{Source}

National Cancer Institute. Refractory Small Lymphocytic Lymphoma. NCI Thesaurus.

Code C8846.

B-cell small lymphocytic lymphoma that is resistant to treatment. 